\title{
Et temanummer om dramaturgi i didaktiske kontekster
}

\author{
Jannike Ohrem Bakke, ${ }^{1}$ Fride Lindstøl ${ }^{\star 1}$ og \\ Kristian Nødtvedt Knudsen ${ }^{2}$ \\ ${ }^{1}$ Universitetet $i$ Sørøst-Norge, Norge; ${ }^{2}$ Universitetet $i$ Agder, Norge \\ Bakke og Lindstøl er likestilte forfattere.
}

Fjer, klekkede egg og spor av fugleføtter markerer en sti inn i klasserommet (En elev tråkker på et eggeskall). Feg hører lyd av fuglekvitter og rytmiske vingeslag (Noen elever ler, ellers stille). På et lerret vises trekkfugler som flyr med lynraske og samstemte formasjoner mot en blå himmel. Fire utstoppede fugler er fordelt på fire stasjoner som er utstyrt med diverse materiell, målebånd, store hvite ark, bøker om fugler (En elev sier «feg hater kråker»). (Fra feltnotat fra forsker, 15.2.21)

Læreren leser høyt: "I lang tid ble fugler regnet som dumme. Små vesener med runde, blanke øyne og peanøtthjerner. Reptiler med vinger. Hønsehjerner som stikker hodet $i$ sanden som strutser. De flyr rett inn $i$ vinduer, hakker på sitt eget speilbilde, krasjer $i$ stromledninger og snubler av sted mot sin egen død». (Lydopptak fra økt, 15.2.21) ${ }^{1}$

Dette anslaget er fra en oppstart på en økt med temaet fugleliv og bærekraft i naturfag på 7. trinn. Læreren har laget en installasjon over "fugleliv», der elever skal arbeide $i$ et forskerteam og undersøke hvordan fugler lever, overlever, trues, utryddes og tilpasser seg natur og klima. Undervisningen ble giennomført i et profesjonsverksted, et fysisk rom og læringslaboratorium, som er utviklet på Universitetet i Sørøst-Norge. I dette verkstedet samarbeider forskere, lærere og lærerskolestudenter om å utvikle, prøve ut og analysere undervisning. For å komponere og analysere undervisningen anvendes dramaturgiske perspektiver.

$\AA$ k kople dramaturgi med undervisning og andre didaktiske kontekster er et felt det er forsket lite på.Vi mener imidlertid at det ligger et stort potensial nettopp her.

\footnotetext{
${ }^{1}$ Læreren leser fra Ackerman, J. (2017). Fuglenes fantastiske liv, innledning, Gyldendal Norsk Forlag.
}

^Korrespondanse: Fride Lindstøl, epost: fride.1.hansen@usn.no

(C) 2021 F. Lindstøl, K. N. Knudsen \& J. O. Bakke. This is an Open Access article distributed under the terms of the Creative Commons Attribution 4.0 International License (https://creativecommons.org/licenses/by-nc/4.0/), allowing third parties to copy and redistribute the material in any medium or format and to remix, transform, and build upon the material for any purpose, even commercially, provided the original work is properly cited and states its license. 
På samme måte som profesjonsverkstedet legger opp til samarbeid og utforsking, har vi gjennom dette temanummeret ønsket å invitere forskere og undervisere til å prøve ut, utvikle og analysere dramaturgiske perspektiver i ulike didaktiske kontekster.

Intensjon bak dette temanummeret i $\mathcal{F} A S E d$ er å styrke dramaturgi som forskningsfelt koplet til klasserommet og andre didaktiske kontekster. I Norge, men også i Norden, har det de siste par tiårene vært en økende interesse for å anvende dramaturgiske perspektiver i blant annet klasserom (se for eksempel Allern, 2010; Bakke, 2019; Bakke \& Lindstøl, 2020; Knudsen, 2018; Lindstøl, 2018; Vangsnes, 2014; T. Østern, 2014; A. L. Østern, 2021). Didaktiske kontekster forstår vi som rom, møteplasser og situasjoner/hendelser der undervisning og læring oppstår, skapes og settes i spill. Formålet med dette temanummeret er å undersøke hvordan dramaturgiske praksiser, dramaturgisk teori, dramaturgisk metode og tilhørende analyser kan supplere og vitalisere undervisning og andre kontekster, som for eksempel både lærerutdanning og kunstfag.

Dramaturgibegrepet er sammensatt av to greske ord: drama, som betyr noe som framstilles, en handling (Heggstad, 2012, s. 15), og ergon, som betyr handling i virksomhet (Braanaas, 2008, s. 335). Det understreker at man i dramaturgien er opptatt av å studere handlinger og praksiser. Tradisjonelt har dramaturgi vært knyttet til scenekunst og teatret, der det for eksempel har dreid seg om å skape handlinger som kan berøre, påvirke og utfordre praksiser, eller måter vi tenker og uttrykker fortellinger og ideer om oss selv eller andre. I nyere tid anvendes dramaturgi i mange kontekster, og det fins flere ulike forskjellige eksempler på dramaturgisk praksis (Pewny et al., 2014; Romanska, 2016). I skolens praksiser blir for eksempel handlinger styrt av eksterne mål og innholdskriterier. Det er «noe» som skal læres og vurderes på en eller annen måte. Ofte er det samsvar mellom lærerens intensjoner og mål og deltakernes opplevelse av mening og læring. Andre ganger kan spenninger og konflikter oppstå og skape forflytninger og brudd som er nødvendige for at endring, utvikling og læring kan skje. Dramaturgiske perspektiver kan gi oss som lærere, ledere og forskere noen refleksjonsrammer og praktiske innganger til å planlegge, gjennomføre og forske på undervisning og andre didaktiske kontekster.

Dramaturgisk teori brukes til å analysere alle typer iscenesettelser og presentasjoner som foregår innenfor og utenfor teater, film og fiksjonsfortellinger (Allern, 2015, s. 35). Slik teori kan brukes både til å beskrive, undersøke og diskutere det en lærer, fasilitator og formidler gjør. Fordi dramaturgisk teori brukes til å undersøke, forklare og analysere samspill mellom visuelle, kroppslige, affektive, muntlige, skriftlige og fiksjonelle handlinger, har dramaturgistudier ofte et eget laboratorium der ulike dramaturgiske innganger og valg kan observeres og prøves ut (Lehmann, 1996; Szatkowski, 1989). Dette temanummeret kan også ses på som et slik laboratorium. I tillegg tilbyr dramaturgisk teori begreper som kan brukes til å analysere handlingers potensielle virkninger, for eksempel sammenhenger mellom dramaturgiske valg og læring. 
Dramaturgisk metode har etablert et skille mellom planlegging, gjennomføring og resepsion av undervisning. Det er uttrykt som ulike analyseområder (Szatkowski, 1989). I undervisning og andre didaktiske kontekster kan dramaturgiske metoder eller tilnærminger blant annet benyttes for å forklare komposisjonelle trekk ved et forløp. Vi kan for eksempel studere en idé som ligger til grunn for et forløp, og se på hvordan den realiseres. Vi kan studere et forløp satt i spill, både hendelser, faser og hele forløp. Vi kan undersøke resepsionen av forløpet, det vil si hvordan forløpet oppleves/erfares, og hva som sitter igjen av kunnskap eller erfaring. En bærende idé for dramaturgisk metode er å forbinde handling, iscenesettelse og teori - å gjøre, analysere og reflektere.

Dramaturgiske analyser kan være analyser av forløp, faser og hendelser (Bakke \& Lindstøl, 2021; Knudsen, 2017), og de tilbyr et språk, hentet fra teatervitenskapen, for å forske på undervisning og andre didaktiske kontekster. Gjennom å utforske og systematisere dramaturgiske praksiser og språk kan vi avdekke muligheter og handlingsrom i ulike didaktiske rom og møteplasser. Vi kan identifisere og videreutvikle mønster, rutiner, brudd og strukturer og samarbeide om å skape et bredt og rikt handlingsrepertoar for undervisere, studenter, elever og forskere.

Artiklene som blir presentert i dette temanummeret, spenner bredt. De beskriver og undersøker ulike kontekster, og de anvender ulike vitenskapsteoretiske perspektiver, metoder og analyseformer. Det fins både teoretiske og empiriske studier. Artiklene har likevel flere fellestrekk, som kan si noe om et felles bidrag:

1. I artiklene er praksis og teori er tett forbundet.

2. Ulike dramaturgiske innganger, som kropp, rom, tekst og tid, er inkludert i analysen.

3. Dramaturgi handler om å se muligheter og sammenhenger mellom valg og virkning, form og innhold og intensjon og opplevelse. Det fins mange muligheter, ikke én.

4. Spenninger mellom ulike fag, undervisningssyn, elevsyn, teatersyn og praksiser settes i spill og er en ressurs. Harmoni er ikke nødvendigvis et mål, tvert imot kan brytninger og rystelser også skape rom for læring.

5. Dramaturgiske valg som tas i planlegging og gjennomføring av undervisning har betydning for hvilke kunnskaper og læreprosesser som settes i spill, det vil si at dramaturgiske valg har epistemologisk betydning.

I det videre presenteres hver artikkel kort:

I den første artikkelen, «En nomadisk tidsreise om dramaturgi i didaktisk kontekst», presenterer og analyserer Anna-Lena Østern tre dramaturgiske modeller som hun har utviklet i perioden 1998 til 2021. Med modellene som teoretiske og empiriske nedslagsfelt undersøker hun hvordan disse bærer spor av den reisen forfatteren har gjort som lærerutdanner og den utviklingen som har skjedd med tanke på synet på utdannelse, utdanningspolitikk, elevrolle og lærerrolle, fagteori og vitenskapsteori - både 
internasjonalt og nasjonalt. Østern bruker 'performance writing' innenfor et performativt forskningsparadigme som strukturerende tilnærming.

I den andre artikkelen, «Mellom entré og sorti - dramaturgisk didaktikk i klasserommet», skriver Kristin Helstad og Per Arne Øiestad om hvordan det å tenke som en dramaturg kan bidra til å bevisstgjøre og profesjonalisere didaktisk arbeid og undervisning. De undersøker og foreslår en sirkulær dramaturgisk didaktikk som kan forklare og belyse hvordan læreren kan tilrettelegge for at elever arbeider faglig og relasjonelt $i$ et klassefellesskap. Artikkelen bidrar blant annet med å bringe didaktikk og dramaturgi nærmere hverandre gjennom å tilby en dramaturgisk modell som kan brukes til å reflektere over undervisning og læring i og på tvers av didaktiske kontekster.

I den tredje artikkelen, «Ser du gorillaen i rommet? - om å undervise i observasjon ved bruk av fiksjonalisering», undersøker Jannike Ohrem Bakke og Fride Lindstøl hvordan lærerstudenter trener på observasjon som ferdighet og metode for å forberede seg til observasjonspraksis i skolen. Treningen foregår i et profesjonsverksted, en arena for undervisning og forskning. Undervisningen er sentrert rundt ulike former for fiksjonalisering, som i denne sammenhengen betyr hvordan lærerutdannere bruker rom, kropp, tid og tekst til å iscenesette forestilte hendelser fra klasserommet. De anvender dramaturgiske analyser for å se på undervisningsforløp og hendelser i observasjon. Artikkelen er et praktisk bidrag til lærerutdannere som underviser i observasion som ferdighet og metode.

Den fjerde artikkelen, «Om øvelsens betydning som dramaturgisk tilnærming i undervisning av performancekunst», er en empirisk studie av et universitetskurs i performancekunst på Norges arktiske universitet. Kristina Junttila undersøker hvordan øvelser kan være det bærende dramaturgiske elementet i undervisningen. Analysen avdekker tre områder som har betydning for øvelsene - kroppslighet, materialitet og sted. I artikkelen pekes det på viktigheten av å initiere øvelser som aktiverer studentene til å eksperimentere slik at de får redskaper til å bli aktive medspillere i å skape framtidas performancekunst.

I den femte artikkelen, "Faciliteringens dramaturgi i affektive rum», undersøker Ida Krøgholt fasilitering som dramaturgisk kommunikasjon med vekt på affektive og kroppslige sider av kommunikasjonen. Gjennom en empirisk analyse av én samarbeidsøvelse i én teaterpedagogisk workshop, undersøker hun hvordan affektteori kan brukes til å observere og analysere sider av lederens fasilitering. I forlengelsen av analysen genereres begreper som kan brukes til å fremheve kroppslige og affektive sider av kommunikasjon og teaterpedagogisk fasilitering. Krøgholdt argumenterer for at affektteori kan anvendes til å analysere fasiliteringsarbeid i relasjon til organisasjonsledelse, kunstproduksjon og pedagogikk.

Den sjette artiklelen, «'For a few minutes I could pretend I was someone else’ - a study of multiple approaches to fiction reading activities», er en empirisk studie om fiktive lesemåter, gjennomført med elever på 8. trinn. Jannike Ohrem Bakke og Fride Lindstøl undersøker et leseforløp der elever på ulike måter må ta stilling til en novelle. De ser på hva undervisningskomposisjon gjør med tekstforlegg og leseopplevelse. Leseforløpet 
analyseres med dramaturgiske analysemåter som først viser hele forløpet, og deretter enkelte aktiviteter i det. Artikkelen er et praktisk og metodisk bidrag til lærere og klasseromforskere som tar i bruk dramaturgiske analyser av undervisning for å få innsikt $\mathrm{i}$ sammenhenger mellom dramaturgiske valg og elevenes lesemåter og leseopplevelser. Den viser også at erfaringsbaserte lesemåter kan være en bro til analytiske lesemåter.

Til sammen danner artiklene et bilde av et vitalt, innovativt, interdisiplinært, flerstemmig, åpent og flyktig forskningsfelt med mange muligheter for å erobre mark i framtiden. Artiklene bidrar med ny kunnskap til forskere, lærere, studenter og formidlere som ønsker å forske på egen og andres undervisning.

Bakkenteigen \& Kristiansand, 29. 05. 2021

Redaktører for temanummeret Dramaturgiske perspektiver på didaktiske kontekster Jannike Ohrem Bakke

Kristian Nødtvedt Knudsen

Fride Lindstøl

\section{Referanser}

Ackerman, J. (2017) Fuglenes fantastiske liv. Gyldendal.

Allern, T.-H. (2015). Dramaturgi i undervisning og læring. I H. Kjelen (Red.), Det utvidede lceringsrommet (s. 31-56). Fagbokforlaget.

Allern, T.-H. (2010). Dramaturgy in teaching and learning. I A. L. Østern, M. Björkgren \& B. Snickars-von Wright (Red.), Drama in three movements: A Ulyssean encounter (s. 95-111). Åbo Akademi University.

Bakke, J. O. (2019). Skriveforløpets dramaturgi: A iscenesette et skriveoppdrag. En kvalitativ studie av skriveundervisning $i$ norsk, samfunnsfag og naturfag på 7. trinn, gjennomført $i$ Normprosjektet [Doktorgradsavhandling, Universitetet i Sørøst-Norge]. USN Open Archive. http://hdl.handle.net/11250/2582386

Bakke, J. O. \& Lindstøl, F. (2021) Chasing fleeing animals - on the dramaturgical method and the dramaturgical analysis of teaching, Research in Drama Education: The fournal of Applied Theatre and Performance, 26(2), 283-299. https://doi.org/10.1080/13569783.2021.1885370

Braanaas, N. (2008). Dramapedagogisk historie og teori. Fagbokforlaget.

Heggstad, K. M. (2012). 7 veier til Drama: Grunnbok $i$ dramapedagogikk for lerere $i$ barnehage og skole (3. utg.). Fagbokforlaget.

Knudsen, K. N. (2017). Performative læringsrum på digitale scener - dramadidaktik og sociale medier. Fournal for Research in Arts and Sports Education, 1(1), 1-16. https://doi.org/10.23865/jased.v1.482

Knudsen, K. N. (2018). Challenging fiction: Exploring meaning-making processes in the crossover between social media and drama in education. International fournal of Education and the Arts, 19(1), 1-24. https://doi.org/10.18113/P8ijea 1901

Lehmann, N. (1996). Dekonstruktion og dramaturgi. Aarhus Universitetsforlag.

Lindstøl, F. (2018). Mellom risiko og kontroll - dramaturgiske perspektiver på lererutdanneres undervisning [Doktorgradsavhandling, Universitetet i Sørøst-Norge]. USN Open Archive. http://hdl.handle.net/11250/ 2564049

Pewny, K., Callens, J. \& Coppens, J. (Red.). (2014). Dramaturgies in the new millenium. Relationality, performativity and potentiality. Narr Verlag.

Romanska, M. (Red.). (2015). The Routledge companion to dramaturgy. Routledge.

Szatkowski, J. (1989). Dramaturgiske modeller - om dramaturgisk tekstanalyse. I E. E. Christoffersen, T. Kjølner \& J. Szatkowski (Red.), Dramaturgisk analyse: En antologi (s. 9-92). Universitetet i Aarhus, Institutt for dramaturgi.

Vangsnes, V. (2014). The dramaturgy and didactics of computer gaming. A study of a medium in the educational context of kindergartens [Doktorgradsavhandling, Universitetet i Bergen]. BORA. https://hdl.handle.net/1956/8304

Østern, T. (2017). Å forske med kunsten som metodologisk praksis med aesthesis som mandat. fournal for Research in Arts and Sports Education, 1(5). https://doi.org/10.23865/jased.v1.982

Østern, A. L. (2021). (Red.). Teaching and learning through dramaturgy. Education as a an artful engagement. Routledge. 